\title{
Prognostic Factors in Breast Cancer Patients with Brain Metastases: Retrospective Analysis
}

\author{
Ramy Ghali ${ }^{1}$, Ahmed Gaballah ${ }^{1}$, Essam Saleh ${ }^{1}$, Aamer Arif ${ }^{2}$ \\ ${ }^{1}$ Clinical Oncology Department, Faculty of Medicine, Ain Shams University, Cairo, Egypt; ${ }^{2}$ Ramadi \\ General Hospital, Anbar, Iraq
}

Background: Breast cancer is first cause of cancer-related deaths and it is estimated that $15 \%$ of breast cancer patients will develop brain metastases (BM). Its incidence differs according to many factors like molecular subtypes and burden and duration of systemic disease. Triple negative disease is an aggressive subtype with lifetime BM incidence of 25-46\%. Survival of patients with BM is generally poor and affected by molecular subtypes, patient's performance, number and burden of visceral metastasis and resectability of brain lesions.

Aim: This analysis aimed at evaluating the prognostic factors in breast cancer patients with BM.

Methods: We retrospectively reviewed breast cancer patients' files treated at a single institute between January 2010 and December 2014. From 2095 files reviewed, 32 had BM. The clinico-epidemiological, pathological, treatment received and survival data were extracted and analysed.

Results: Median age at BM diagnosis was 49.5 years (range 27-69). Median time from breast cancer diagnosis to BM diagnosis was 16 months (95\% CI: 13.23-18.77). Postmenopausal women represented 59\% of patients and 56\% of them had a good performance status (ECOG 1-2). The majority of patients had grade II disease and invasive ductal carcinoma (65.6\% and $81.3 \%$, respectively). The tumor subtype was hormone receptor positive/HER2-neu negative in $25 \%$, triple negative in $25 \%$ and HER2-neu positive in $50 \%$. More than $2 / 3$ of patients presented with signs of increased intracranial tension. Seven (22\%) patients had single BM lesion, 22 (69\%) had multiple lesions and 3 (9\%) had concomitant leptomeningeal metastases. Three $(9 \%)$ patients underwent brain metastatectomy. The median progression free survival was 4.5 months (95\% CI: 3.58-5.42) and was significantly longer among patients who underwent metastatectomy $(\mathrm{p}=0.023)$ and those with hormone receptor-positive disease $(\mathrm{p}=0.007)$. The median overall survival was 6.5 months $(95 \%$ CI: 4.23-9.77) and was significantly longer in patients with better performance status (ECOG 1), hormone receptor-positive disease, low number of metastatic sites and brain metastatectomy ( $\mathrm{p}=0.037,0.045,<0.001$ and 0.007 ; respectively).

Conclusion: Brain metastases in breast cancer patients is an indicator of short survival which is influenced by tumor subtype, performance status, burden of systemic disease and ability to perform metastatectomy.

Keywords: Metastatic breast cancer, Prognostic factors, Brain metastases

Corresponding author: Ramy Ghali, MD, Clinical Oncology Department, Faculty of Medicine, Ain Shams University, Cairo, Egypt; Email: ramyghali@ hotmail.com

Submitted: 30-March-2018, Revised: 23-April-2018, Accepted: 25-April-2018, Published Online: 21-May-2018

\section{INTRODUCTION}

Brain metastases (BM) secondary to breast cancer affect badly the general condition of patients and may cause serious morbidity and eventually mortality if undiagnosed or not properly treated. Hence, it may be advisable to predict the occurrence of $\mathrm{BM}$ in breast cancer patients ${ }^{1}$. Early diagnosis of BM may help in improving treatment outcome and decreasing disease burden on the patients.

In breast cancer, BM is frequently encountered in later stages following metastases to other organs ${ }^{2}$. Brain metastases secondary to breast cancer is associated with poor survival of patients in general. The survival of these patients may be affected by factors including molecular subtypes, performance status, ressectability of BM and visceral metastasis burden. When detected, its treatment is usually difficult and unfortunately has reverse effects on life expectancy ${ }^{3}$.
The aim of this study was to describe the pattern of $\mathrm{BM}$ in breast cancer patients and to evaluate factors associated with prognosis.

\section{METHODS}

The files of patients with breast cancer metastatic to the brain treated at the Department of Clinical Oncology and Nuclear Medicine, Ain Shams University in the period from January 2010 to December 2014 were retrospectively reviewed.

Adult patients (>18 years old) with pathologically proven breast cancer and radiological documentation of $\mathrm{BM}$ who had been followed up for at least 6 months were eligible for analysis. Patients without full medical data and those with previous or concurrent diagnosis of second primary malignancy were excluded.

The following was collected from the patients' files: personal, clinico-pathological and tumor related data as well as the treatment given and its outcome. Tumor 
response was assessed using the Response Evaluation Criteria In Solid Tumors (RECIST) criteria.

Time to BM (TTBM) was defined as the time from primary breast cancer diagnosis to the date of $\mathrm{BM}$ diagnosis ${ }^{4}$. Progression-free survival (PFS) was defined as the time from BM diagnosis till progression or death and overall survival (OS) as the time from BM diagnosis till death.

Recorded data were analyzed using the statistical package for social sciences, version 20 (SPSS Inc., Chicago, Illinois, USA). Quantitative data were expressed as mean \pm standard deviation (SD) and qualitative data as frequency and percentage. KaplanMeier survival analysis was used to examine the distribution of time-to-event variables and log rank test to compare time-to-event variables by levels of a factor variable. P-value <0.05 was considered significant.

\section{RESULTS}

During the study period, 32 out of 2095 (1.53\%) breast cancer patients developed BM.

Table 1: Personal and tumor characteristics of 32 patients at the time of diagnosis of brain metastases

\begin{tabular}{|c|c|c|}
\hline \multicolumn{3}{|l|}{ Characteristic } \\
\hline \multicolumn{3}{|l|}{ Age (years) } \\
\hline \multirow{3}{*}{$\begin{array}{l}\text { Mean } \pm \text { SD } \\
\text { Median (range) } \\
\end{array}$} & \multicolumn{2}{|c|}{$48.7 \pm 11.39$} \\
\hline & \multicolumn{2}{|c|}{$49.5(27-69)$} \\
\hline & No. & $\%$ \\
\hline$\leq 48$ & 15 & 46.9 \\
\hline$>48$ & 17 & 53.1 \\
\hline \multicolumn{3}{|l|}{ Menopausal status } \\
\hline Premenopausal & 13 & 40.6 \\
\hline Postmenopausal & 19 & 59.4 \\
\hline \multicolumn{3}{|l|}{ Family history of breast cancer } \\
\hline Positive & 2 & 6.3 \\
\hline Negative & 30 & 90.3 \\
\hline \multicolumn{3}{|l|}{ ECOG performance status } \\
\hline 1 & 7 & 21.9 \\
\hline 2 & 11 & 34.4 \\
\hline 3 & 14 & 43.8 \\
\hline \multicolumn{3}{|l|}{ Tumor grade } \\
\hline 1 & 4 & 12.5 \\
\hline 2 & 21 & 65.6 \\
\hline 3 & 7 & 21.9 \\
\hline \multicolumn{3}{|l|}{ Histological subtype } \\
\hline Invasive duct carcinoma & 26 & 81.3 \\
\hline Invasive lobular carcinoma & 3 & 9.4 \\
\hline Other* & 3 & 9.4 \\
\hline \multicolumn{3}{|l|}{ Tumor subtype } \\
\hline HR-positive / HER2-negative & 8 & 25 \\
\hline Triple negative & 8 & 25 \\
\hline $\begin{array}{l}\text { HER } 2 \text {-positive irrespective of } \\
\text { HR status }\end{array}$ & 16 & 50 \\
\hline
\end{tabular}

* Mixed, medullary, papillary and cribriform tumors; ECOG: Eastern Cooperative Oncology Group; HR: Hormonal receptor.

Personal and tumor characteristics of patients at the time of diagnosis of BM are shown in table 1. Only 2 cases had positive family history of breast cancer. Both cases were 41 years old. The $1^{\text {st }}$ case had $1^{\text {st }}$ degree breast cancer (mother) while the $2^{\text {nd }}$ case had $2^{\text {nd }}$ degree (aunt). None of the patients had grade 0 or 4 Eastern Cooperative Oncology Group (ECOG) performance scale.

Characteristics and treatment of BM are illustrated in table 2. The majority of patients presented with manifestations of increased intracranial tension (headache, vomiting and blurring of vision), had multiple BM and other distant metastatic sites, and received radiotherapy as the primary treatment for BM.

Table 2: Brain metastases' characteristics at presentation and their primary treatment

\begin{tabular}{lll}
\hline & No. & $\%$ \\
\hline Presenting symptoms & & \\
\hline $\begin{array}{l}\text { Manifestations of increased } \\
\text { intracranial tension }\end{array}$ & 22 & 68.7 \\
\hline Neurological deficit & 5 & 15.6 \\
\hline Convulsions & 1 & 3.1 \\
\hline Asymptomatic & 4 & 12.5 \\
\hline Pattern of BM & & \\
\hline Single & 5 & 15.6 \\
\hline$\quad$ Frontal & 1 & 3.1 \\
\cline { 2 - 3 } Parietal & 1 & 3.1 \\
\hline Occipital & 22 & 68.8 \\
\hline Multiple & 3 & 9.3 \\
\hline With leptomeningeal infiltration & & \\
\hline Distant metastases at BM diagnosis & 9 & 28.1 \\
\hline No & 23 & 71.8 \\
\hline Yes & &
\end{tabular}

Number of distant metastasis sites at BM diagnosis

\begin{tabular}{lll}
\hline 1 & 11 & 34.3 \\
\hline 2 & 6 & 18.7 \\
\hline 3 & 1 & 3.1 \\
\hline$>3$ & 5 & 15.6 \\
\hline
\end{tabular}

Timing of metastases

Metastatic from the start

\begin{tabular}{lll} 
Brain & 2 & 6.2 \\
\hline Bone, liver and lung & 1 & 3.1 \\
\hline Lung & 1 & 3.1 \\
\hline Developed metastases later on & 28 & 87.4 \\
\hline
\end{tabular}

Primary treatment of BM

\begin{tabular}{lll} 
Surgery (mass excision) & 3 & 9.4 \\
\hline Radiotherapy & 26 & 81.2 \\
\hline Chemotherapy & 3 & 9.4 \\
\hline
\end{tabular}

BM: brain metastases

The median follow-up time was 10 months after diagnosis of BM. The Median Time to Brain metastasis (TTBM) was 16 months (95\% CI: 13.23 -18.77). The median PFS of the 32 patients with BM was 4.5 months (95\% CI: 3.576 -5.424) (figure1) and the median OS was 6.5 months (95\% CI: 4.228-9.772) (figure 2). The 1-year survival rate was $23 \%$ and the 2 -year was $3 \%$.

Univariate analysis of PFS and OS is illustrated in table 3. Regarding PFS, it differed significantly according to the tumor subtype being shortest in patients with triple negative subtype. Significantly longer median PFS was observed in patients who underwent metastatectomy compared to patients with no metastatectomy. The other studied variables did not correlate significantly with PFS. 
Regarding OS, it was significantly shorter in association with poorer performance status at BM diagnosis, triple negative subtype, no BM metastatectomy and higher number of other distant metastatic sites at BM diagnosis.

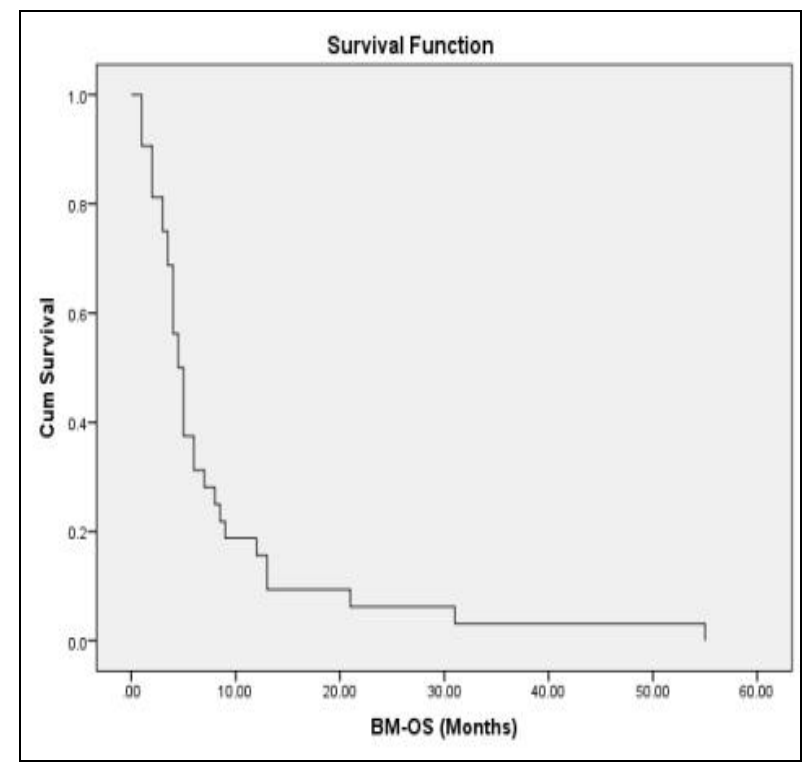

Figure 1: Progression free survival curve of 32 patients with brain metastases

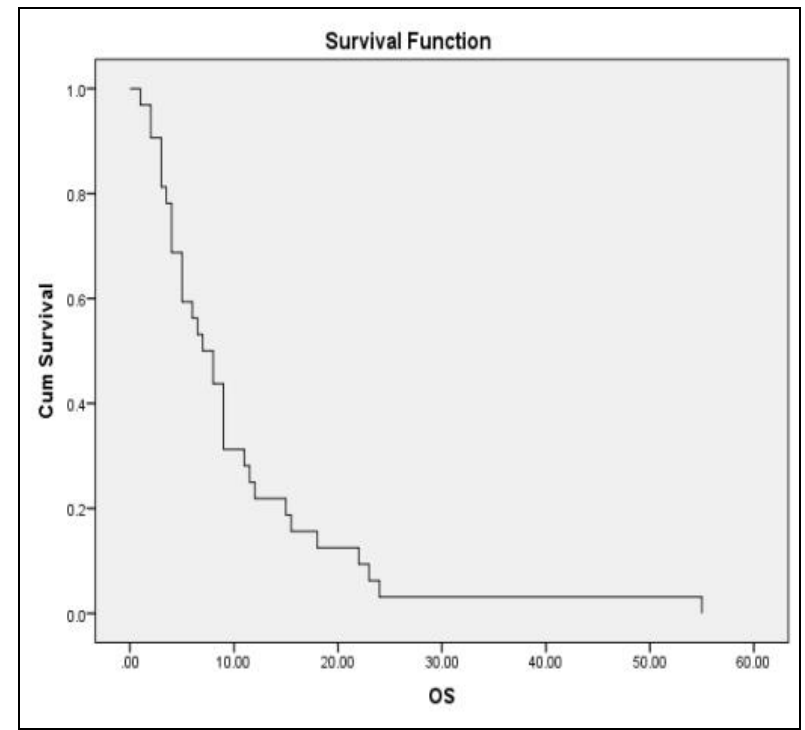

Figure 2: Overall survival curve of 32 patients with brain metastases

\section{DISCUSSION}

This was a retrospective analysis of 32 female patients with breast cancer metastatic to brain treated in a single institution.

This relatively low prevalence of BM could be attributed to the relatively short follow up period of patients. Also patients with files not containing full medical data were excluded.

In general, the characteristics of our study population were more or less similar to that reported in other studies. The median age at diagnosis of BM was
49.5 years which is similar to that reported by Ahn et al (48 years) ${ }^{4}$ and Dayan et al (49 years) ${ }^{1}$.

Fifty-nine percent of patients included in the current study were postmenopausal, similar to that reported by Gunduz et al (58\%) ${ }^{5}$. Also, Yücel's et al found that postmenopausal women were more than premenopausal in their study ${ }^{6}$.

In our study, the majority (78\%) of patients had an ECOG performance scale $>1$ at the time of $\mathrm{BM}$ diagnosis which is close to the $72 \%$ reported by Ahn et al ${ }^{4}$. Similarly, in their literature review about BM of breast cancer origin, Rostami et al found that most patients presented with a higher $(>70 \%)$ KPS score (equivalent to ECOG 0-1) ${ }^{7}$. In contrast, Yücel et al described that $68 \%$ of cases were ECOG $\leq 2{ }^{6}$. Poor performance status at presentation may be explained by lack of health education and socioeconomic factors leading to delay in seeking medical advice.

Grade 2 and 3 tumors represented $87 \%$ of our population which is higher than that reported by Rostami et al $(73 \%)^{7}$. Invasive ductal carcinoma was the most prevalent histological diagnosis in our patients. A similar study, reported that invasive duct carcinoma constitute $81 \%$ and invasive lobular carcinoma constitute $7 \%$ in private pathological material ${ }^{8}$. This is going with most of studies discussing breast cancer metastasis $6,7,9$.

Half of the patients in this study had HER2-positive irrespective of HR-status disease. This is consistent with the findings of Leone et al who observed HER2 overexpression in $45 \%$ of $\mathrm{BM}$ cases compared with the $20 \%$ incidence of HER 2 overexpression in all cases with breast cancer, with $25 \%$ incidence of luminal A tumors, and $30 \%$ incidence of triple-negative disease ${ }^{10}$. This confirms that patients with HER2-overexpression are at increased risk of $\mathrm{BM}$ development and it is important to take this into consideration during individual's follow-up 10-12. This may be contributed to the ability of HER2cancer cell to spread hematogenously ${ }^{13}$. The pattern of $\mathrm{BM}$ in the current study is more or less similar to that described by Evans et al who reported $78 \%$ prevalence of multiple metastases, $14 \%$ solitary metastases and $8 \%$ leptomeningeal metastases ${ }^{14}$. Like what had been described in another study, the majority of the population of this study had pre-existing distant metastases to other sites at the time of BM diagnosis ${ }^{15}$.

We found that only undergoing metastatectomy and hormone receptor-positive disease were associated with significantly better PFS. When breast cancer patients with BM were grouped according to the tumor subtype, Arslan et al found that PFS is shortest in patients with triple negative disease and longest in hormone receptor positive ${ }^{16}$. This was also in concordance with the study conducted by Huang et al ${ }^{17}$.

The median OS in this study was 6.5 months and was significantly longer with better performance status, low number of other metastatic sites and metastatectomy. Shorter OS was observed in triple negative patients compared to hormone receptorpositive.

The significant relation between BM secondary to breast cancer and its biological subtypes has been described in many studies $13,18-20$. In addition to the 
Table 3. Univariate analysis of progression free survival and overall survival of 32 breast cancer patients with brain metastases

\begin{tabular}{|c|c|c|c|c|c|c|c|}
\hline \multirow[t]{2}{*}{ Variables } & \multirow[t]{2}{*}{ No. $(\%)$} & \multicolumn{2}{|c|}{$\begin{array}{l}\text { Progression free survival } \\
\text { (months) }\end{array}$} & \multirow[t]{2}{*}{ P value* } & \multicolumn{2}{|c|}{$\begin{array}{l}\text { Overall survival } \\
\text { (months) }\end{array}$} & \multirow[t]{2}{*}{ P value* } \\
\hline & & Median & $95 \% \mathrm{CI}$ & & Median & $95 \% \mathrm{CI}$ & \\
\hline \multicolumn{8}{|l|}{ Age at BM diagnosis } \\
\hline$\leq 48$ years & $15(46.9)$ & 4.5 & $3.08-5.92$ & \multirow[t]{2}{*}{0.44} & $3 . .8$ & $0.99-6.61$ & \multirow[t]{2}{*}{0.345} \\
\hline$>48$ years & $17(53.1)$ & 4.6 & $3.26-5.94$ & & $\overline{9}$ & $4.2-13.8$ & \\
\hline \multicolumn{8}{|l|}{ Menstrual history } \\
\hline Premenopause & $13(40.6)$ & 5 & $3.85-6.15$ & \multirow[t]{2}{*}{0.411} & 10.26 & $2.56-24.9$ & \multirow[t]{2}{*}{0.537} \\
\hline Postmenopause & $19(59.4)$ & 4.5 & $2.94-6.06$ & & $\overline{4}$ & $1-9.69$ & \\
\hline \multicolumn{8}{|l|}{$\begin{array}{l}\text { ECOG performance status at BM } \\
\text { diagnosis }\end{array}$} \\
\hline 1 & $7(21.9)$ & 8 & $2.8-10.8$ & \multirow[t]{3}{*}{0.165} & 12 & $3-29.96$ & \multirow[t]{3}{*}{0.037} \\
\hline 2 & $11(34.4)$ & 5.1 & $3.39-5.81$ & & 8 & $4.76-11.24$ & \\
\hline 3 & $14(43.8)$ & 4.1 & $1.67-5.33$ & & 6 & $3.25-8.75$ & \\
\hline \multicolumn{8}{|l|}{ Tumor grade } \\
\hline 1 & $4(12.5)$ & 5 & $3.72-6.28$ & \multirow[t]{3}{*}{0.22} & 7 & $1.12-12.88$ & \multirow[t]{3}{*}{0.521} \\
\hline 2 & $21(65.6)$ & 4.5 & $3.27-5.73$ & & 8 & $2.07-13.93$ & \\
\hline 3 & $7(21.9)$ & 3 & $0.06-5.94$ & & 6.5 & $2.65-10.35$ & \\
\hline \multicolumn{8}{|l|}{ Histological subtype } \\
\hline Invasive duct carcinoma & $26(81.3)$ & 4.5 & $3.4-5.6$ & \multirow[t]{3}{*}{0.2} & 9 & $3.51-12.49$ & \multirow[t]{3}{*}{0.518} \\
\hline Invasive lobular carcinoma & $3(9.4)$ & 3.00 & $1.05-7$ & & 8 & $5.6-10.4$ & \\
\hline Others & $3(9.4)$ & 13.00 & $4.55-17.55$ & & 5 & $2.99-10.61$ & \\
\hline \multicolumn{8}{|l|}{ Tumor subtype } \\
\hline HR-positive /HER2-Negative & $8(25)$ & 6.50 & $2.27-10.14$ & \multirow[t]{3}{*}{0.007} & 9 & $7.66-10.34$ & \multirow[t]{3}{*}{0.045} \\
\hline Triple negative & $8(25)$ & 3 & $0.92-5.08$ & & 4 & $2.7-6.3$ & \\
\hline $\begin{array}{l}\text { HER 2- Positive irrespective of HR } \\
\text { status }\end{array}$ & $16(50)$ & 4 & $3.72-5.28$ & & 8 & $5.65-11.35$ & \\
\hline \multicolumn{8}{|l|}{ BM metastatectomy } \\
\hline Yes & $3(9.4)$ & 31 & $0-75.81$ & \multirow[t]{2}{*}{0.023} & 31 & $7.12-64.61$ & 0.007 \\
\hline No & $29(90.6)$ & 4.50 & $3.45-5.55$ & & 5 & $4.12-5.88$ & \\
\hline Other metastatic sites at BM diagnosis & & & & & & & \\
\hline Yes & $23(71.9)$ & 4.50 & $2.95-6.05$ & 0.459 & 8 & $5.7-10.3$ & 0.157 \\
\hline No & $9(28.1)$ & 6 & $3.08-8.92$ & & 5 & $2.93-7.07$ & \\
\hline $\begin{array}{l}\text { Number of other metastatic sites at } \\
\text { BM diagnosis }\end{array}$ & & & & & & & \\
\hline 1 & $14(43.8)$ & 9 & $3.15-12.15$ & 0.232 & 9 & 4.11-13.89 & $<0.001$ \\
\hline 2 & $11(34.4)$ & 7 & $6.3-7.7$ & & 7.5 & $5.07-9.93$ & \\
\hline 3 & $6(18.8)$ & 3.5 & $2.22-4.78$ & & 6 & $3.6-8.4$ & \\
\hline 4 & $1(3)$ & 1 & $0.35-1.35$ & & 4 & $4.31-8.44$ & \\
\hline Multiple BM lesions & & & & & & & \\
\hline Yes & $25(78.1)$ & 5 & $3.38-6.62$ & 0.192 & 6 & $5.03-6.97$ & 0.586 \\
\hline No & $7(21.9)$ & 4.5 & $2.74-6.26$ & & 9 & $6.43-11.57$ & \\
\hline
\end{tabular}

* Log rank test; BM: brain metastases; CI: confidence interval; ECOG: Eastern Cooperative Oncology Group; HR: hormone receptor

higher prevalence of BM in association with certain subtypes, these subtypes (triple negative) are associated with poorer survival ${ }^{21}$.

Overall survival in our study was in agreement with that reported by Niwińska et al ${ }^{22}$ and Yücel et al ${ }^{6}(7.5$ and 7 months, respectively).

Andrews et al reported that untreated metastatic breast cancer to brain has a median OS of 4 weeks which may be improved to 4-6 months with whole cranial irradiation. While in patients who had single brain lesion that can be surgically removed or who received stereotactic radiosurgery, the median OS improved dramatically to 16 months ${ }^{23}$.

The 1- and 2-year survival rates in our study were $23 \%$ and $3 \%$ which is similar to the survival rates in Engel et al study with $20 \%$ and $2 \%{ }^{24}$. These low survival rates were confirmed in other studies ${ }^{25,26}$.
As regard performance status, we found a statistically significant relation between ECOG performance status at BM diagnosis and survival which confirms the results of other studies that showed that poor performance status is one of the factors that negatively affect the survival ${ }^{27-31}$.

There was a statistically significant relation between the tumor subtype and survival of breast cancer patients with BM included in this study, a finding that has been described by others ${ }^{32}, 33$. In particular, triple negative breast cancer is associated with dismal OS in patients with $\mathrm{BM}$, ranging from 3 to 4 months ${ }^{34}$. The risk of developing BM is higher among HER2-positive patients, however their survival after BM diagnosis is better than the triple negative and luminal subtypes 35. Some studies reported that the interval for metastasis development, the number of metastasis, and localization 
of metastasis also affect survival ${ }^{36-38}$. Furthermore, the presence of bone and liver metastases was found to be prognostic factor that statistically affect the survival of BM patients ${ }^{39}$. In congruence, the higher the number of metastatic sites other than BM in our patients the shorter the OS.

As regard brain mass excision, our finding support the conclusion of a study done by Yaeger and Nair ${ }^{40}$ in which the presence of a single metastatic lesion in the presence of well-controlled systemic cancer was the best indicator for surgical therapy and was predictive for better survival following resection. This is also supported by the study performed by Patchell et al, in which the addition of surgery followed by radiotherapy compared to WBRT alone reduced significantly the local recurrence in patients with single brain metastases and improved survival ${ }^{41}$.

Prognostic factors that determine the survival of breast cancer patients with BM have been investigated in many studies and some developed prognostic scoring models ${ }^{29}$. The most significant prognosis predictors were age, tumor subtype and performance status ${ }^{42}$.

Limitations of the current study include being a retrospective one that included a relatively small sample size.

\section{Conclusion}

$\mathrm{BM}$ is an indicator of short survival which is influenced by tumor subtype, performance status, burden of systemic disease and the ability to perform metastatectomy. Larger prospective studies are needed to document these findings

\section{Acknowledgement}

The results of this study were presented as a poster at the ESO-ESMO Advanced Breast Cancer $4^{\text {th }}$ International Consensus Conference (ABC4); Lisbon, Portugal, 2-4 November 2017.

\section{Conflict of interest}

The authors have no conflict of interest.

\section{REFERENCES}

1. Dayan A, Koca D, Akman T, Oztop I, Ellidokuz H, Yilmaz U. The factors that have an impact on the development of brain metastasis in the patients with breast cancer. J Cancer Res Ther. 2012; 8(4): 542 -548.

2. Graesslin O, Abdulkarim BS, Coutant C, et al. Nomogram to predict subsequent brain metastasis in patients with metastatic breast cancer. J Clin Oncol. 2010; 28(12): 2032-2037.

3. Oltean D, Dicu T, Eniu D. Brain metastases secondary to breast cancer: symptoms, prognosis and evolution. Tumori. 2009; 95(6): 697- 701.

4. Ahn HK, Park YH, Lee SJ, et al. Clinical implication of Time To Brain Metastasis (TTBM) according to breast cancer subtypes. Springerplus. 2013; 2(1): 136.

5. Gündüz S, Göksu SS, Arslan D, et al. Factors affecting disease-free survival in patients with human epidermal growth factor receptor 2-positive breast cancer who receive adjuvant trastuzumab. Mol Clinical Oncol. 2015; 3(5): 1109-1112.
6. Yücel B, Bahar S, Kaçan T, Şeker M, Celasun M, Bahçeci A. Importance of metastasis site in survival of patients with breast cancer. Austin J Med Oncol. 2014; 1(2): 7.

7. Rostami R, Mittal S, Rostami P, Tavassoli F, Jabbari B. Brain metastasis in breast cancer: a comprehensive literature review. J Neurooncol. 2016; 127(3): 407-414.

8. Farouk O, Ebrahim MA, Senbel A, et al. Breast cancer characteristics in very young Egyptian women $\leq 35$ years. Breast Cancer (Dove Med Press). 2016; 8:53-58.

9. Tayyeb B, Parvin M. Pathogenesis of breast cancer metastasis to brain: a comprehensive approach to the signaling network. Mol Neurobiol. 2016; 53(1): 446-454.

10. Leone JP, Lee AV, Brufsky AM. Prognostic factors and survival of patients with brain metastasis from breast cancer who underwent craniotomy. Cancer Med. 2015; 4(7): 989-994.

11. Kennecke H, Yerushalmi R, Woods R, et al. Metastatic behavior of breast cancer subtypes. J Clin Oncol. 2010; 28(20): 3271-3277.

12. Lin NU, Vanderplas A, Hughes ME, et al. Clinicopathologic features, patterns of recurrence, and survival among women with triple-negative breast cancer in the National Comprehensive Cancer Network. Cancer. 2012; 118(22): 5463-5472.

13. Rorive A, Collignon J, Martin M, André C, Jerusalem G, Coucke P. Breast cancer and brain metastases. Rev Med Liège. 2011; 66(5-6): 299-305.

14. Evans AJ, James JJ, Cornford EJ, et al. Brain metastases from breast cancer: identification of a high-risk group. Clin Oncol (R Coll Radiol). 2004; 16(5): 345-349.

15. Aravantinou-Fatorou E, Skarlos D, Klouvas G, Galani E, Christodoulou C. Long-term survival of patients with breast cancer and brain metastases: 'The experience of the $2^{\text {nd }}$ oncology department of metropolitan hospital and a brief review of the literature'. Forum Clin Oncol. 2015; 6 (1):18-26.

16. Arslan C, Yazici O, Aksoy S, Altundag K. Brain specific progression free survival (bsPFS) according to breast cancer subtypes in patients with brain metastases. J Clin Oncol. 2015; 15 Suppl: e13040.

17. Huang Z, Sun B, Shen G, et al. Brain metastasis reirradiation in patients with advanced breast cancer. J Radiat Res. 2016; 58(1): 142-148

18. Lee JA, Bae JW, Woo SU, Lee JB, Koo BW. Predictive factors and survival rate for brain metastasis from breast cancer. J Breast Cancer. 2008; 11(2): 71-76.

19. Slimane K, Andre F, Delaloge S, et al. Risk factors for brain relapse in patients with metastatic breast cancer. Ann Oncol. 2004; 15(11): 1640-1644.

20. Gaedcke J, Traub F, Milde S, et al. Predominance of the basal type and HER-2/neu type in brain metastasis from breast cancer. Mod Pathol. 2007; 20(8): 864-870.

21. Dawood S, Broglio K, Esteva FJ, et al. Survival among women with triple receptor-negative breast cancer and brain metastases. Ann Oncol. 2009; 20(4): 621-627.

22. Niwińska A, Murawska M, Pogoda K. Breast cancer brain metastases: differences in survival depending on biological subtype, RPA RTOG prognostic class and systemic treatment after whole-brain radiotherapy (WBRT). Ann Oncol. 2010; 21(5): 942-948.

23. Andrews DW, Scott CB, Sperduto PW, et al. Whole brain radiation therapy with or without stereotactic radiosurgery boost for patients with one to three brain metastases: phase III results of the RTOG 9508 randomised trial. The Lancet. 2004; 363(9422): 1665-1672.

24. Engel J, Eckel R, Aydemir U, et al. Determinants and prognoses of locoregional and distant progression in breast cancer. Int J Radiat Oncol Biol Phys. 2003; 55(5): 1186-1195. 
25. Pienkowski T, Zielinski CC. Trastuzumab treatment in patients with breast cancer and metastatic CNS disease. Ann Oncol. 2010; 21(5): 917-924.

26. Hall WA, Djalilian HR, Nussbaum ES, Cho KH. Longterm survival with metastatic cancer to the brain. Med Oncol. 2000; 17(4): 279-286.

27. Dhodapkar MV, Ingle JN, Cha SS, Mailliard JA, Wieand HS. Prognostic factors in elderly women with metastatic breast cancer treated with tamoxifen. Cancer. 1996; 77(4): 683-690.

28. Luoma ML, Hakamies-Blomqvist L, Sjöström J, et al. Prognostic value of quality of life scores for time to progression (TTP) and overall survival time (OS) in advanced breast cancer. Eur J Cancer. 2003; 39(10): 1370-1376.

29. Sperduto PW, Kased N, Roberge D, et al. Summary report on the graded prognostic assessment: an accurate and facile diagnosis-specific tool to estimate survival for patients with brain metastases. J Clin Oncol. 2012; 30(4): 419-425.

30. Ogawa K, Yoshii Y, Nishimaki T, et al. Treatment and prognosis of brain metastases from breast cancer. J Neurooncol. 2008; 86(2): 231-238.

31. Braunstein LZ and Taghian AG. Molecular phenotype, multigene assays, and the locoregional management of breast cancer. Semin Radiat Oncol. 2016; 26(1): 9-16.

32. Hayashi N, Niikura N, Masuda N, et al. Prognostic factors of HER2-positive breast cancer patients who develop brain metastasis: a multicenter retrospective analysis. Breast Cancer Res Treat. 2015; 149(1): 277-284.

33. Rakha EA, El-Sayed ME, Green AR, Lee AH, Robertson $\mathrm{JF}$, Ellis IO. Prognostic markers in triple-negative breast cancer. Cancer. 2007; 109(1): 25-32.
34. Anders CK, Deal AM, Miller CR, et al. The prognostic contribution of clinical breast cancer subtype, age, and race among patients with breast cancer brain metastases. Cancer. 2011; 117(8): 1602-1611.

35. Melisko ME, Moore DH, Sneed PK, De Franco J, Rugo HS. Brain metastases in breast cancer: clinical and pathologic characteristics associated with improvements in survival. J Neurooncol. 2008; 88(3): 359-365.

36. Khanfir A, Lahiani F, Bouzguenda R, Ayedi I, Daoud J, Frikha M. Prognostic factors and survival in metastatic breast cancer: a single institution experience. Rep Pract Oncol Radiother. 2013; 18(3): 127-132.

37. Ren Z, Li Y, Hameed O, Siegal GP, Wei S. Prognostic factors in patients with metastatic breast cancer at the time of diagnosis. Pathol Res Pract. 2014; 210(5): 301-306.

38. Jimeno A, Amador ML, González-Cortijo L, et al. Initially metastatic breast carcinoma has a distinct disease pattern but an equivalent outcome compared with recurrent metastatic breast carcinoma. Cancer. 2004; 100(9): 1833-1842.

39. Jung S, Spiegelman D, Baglietto L, et al. Fruit and vegetable intake and risk of breast cancer by hormone receptor status. J Natl Cancer Inst. 2013; 105(3): 219-236.

40. Yaeger KA, Nair MN. Surgery for brain metastases. Surg Neurol Int. 2013; 4(Suppl 4): S203-S208.

41. Ranasinghe MG, Sheehan JM. Surgical management of brain metastases. Neurosurg Focus. 2007; 22(3): E2.

42. Nieder C, Oehlke O, Hintz M, Grosu AL. The challenge of durable brain control in patients with brain-only metastases from breast cancer. Springerplus. 2015; 4: 585. 